\title{
Possibilities and difficulties for rotorcraft using variable transmission drive trains
}

\author{
H. Amri ${ }^{1}$ R. Feil ${ }^{2} \cdot$ M. Hajek ${ }^{2} \cdot$ M. Weigand ${ }^{1}$
}

Received: 25 March 2015/Revised: 9 March 2016/ Accepted: 10 March 2016/Published online: 31 March 2016

(c) The Author(s) 2016. This article is published with open access at Springerlink.com

\begin{abstract}
This publication shows advantages and possible applications for variable transmission drivetrains within rotorcraft. The power requirement of a generic helicopter with constant and variable rotor speed was calculated. Various drive train technologies that support a variable transmission were described. The prospects of this technology, its influence on the dynamic behaviour of a rotor and further areas that need to be investigated extensively are presented. This technology is applicable to some rotorcraft architecture. Requests from the rotorcraft industry underline the necessity for future rotorcraft using variable rotational speeds. However, the A160 or the EC145 and Mi-8 already show the potential of this technique. Reduction of required power of the rotor should be possible and also an extension of the flight envelope towards higher flight speeds, higher altitudes, better manoeuvrability, etc. By using a variable transmission gearbox, turbine and auxiliary units can still be driven at their design point, independent of the current rotor speed. Excessive loads may occur when discrete speed transmission are used. Frictional or fluid transmissions with continuous variable ratio may fail due to overheating. Other continuous concepts are favoured. The design of a variable speed rotor focuses specifically on its dynamic behaviours and on structural and geometrical optimisation to avoid operation at rotational speed resonance frequencies. Morphing structures
\end{abstract}

This paper is based on a presentation at the German Aerospace Congress, September 16-18, 2014, Augsburg, Germany.

H. Amri

hanns.amri@tuwien.ac.at

1 Vienna University of Technology-IKL, Getreidemarkt 9, 1060 Vienna, Austria

2 Technical University of Munich-HT, Boltzmannstr. 15, 85748 Garching, Germany may support this. Some rotorcraft architectures can benefit from a variable speed rotor technology. It probably will increase efficiency, decrease noise levels, fuel consumption and $\mathrm{CO}_{2}$ production, and the flight envelope may be extended.

Keywords Variable speed rotor - Variable transmission drivetrain - Power optimisation - Economic rotor craft . Flight envelope extension - Future technology

\section{Introduction}

Current research indicates the necessity for variable speed rotor technologies in future rotorcraft. However, there are questions that are yet to be addressed. For example: (1) How much can performance be increased? and (2) How can such a system be realised according to the requirements and needs of a modern rotorcraft? This paper summarises the state of the art and performs preliminary analyses to address these questions.

\subsection{Hummingbird}

Boeing's A160 Hummingbird is a good example of how the efficiency and the flight envelope of a rotorcraft can be influenced by varying the rotor speed using two gears. The unmanned air vehicle is shown in Fig. 1. In May 2008 the A160 set a new record in endurance flight in its class. The vehicle was airborne for $18.7 \mathrm{~h}$ [1]. This performance was accomplished ability to shift to another gear and by specially constructed rotor blades that support two rotor speeds by avoiding critical rotor dynamical behaviour in this special case. The dynamical behaviour of a rotor using different RPM is still problematic. The rotor and the blades 


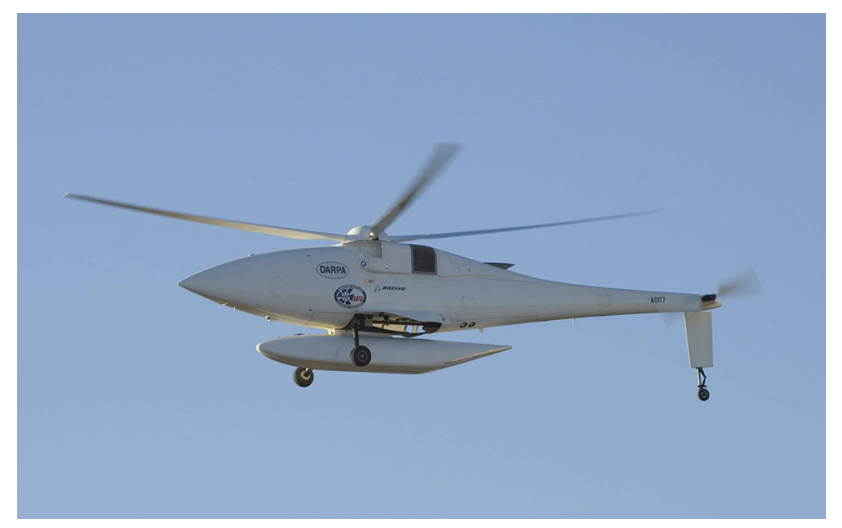

Fig. 1 Boeing A160 Hummingbird [US Army: Boeing A160 Hummingbird (2001)]

were designed according to the invention, called "Optimum Speed Rotor Technology", proposed by Karem [2]. Karem invented a method of designing radially extending light and stiff blades which can be operated at different RPM.

\subsection{Variable RPM turbine}

Airbus Helicopters invented a so-called VATROMS (Variable rotor speed and torque matching system) for the helicopter BK117-C2, also called EC145 or H145 (given in Fig. 2). It is a control system regulating the driving speed of the turbine. The system controls the rotor speed, based on air density and flight speed. Furthermore, the torques delivered by the two turbines are balanced. The goal was to improve handling qualities and reduce noise, especially in urban areas. A speed range of $96.5-103.5 \%$ of the nominal RPM was shown to be possible [3].

The Mi-8 helicopter class and its modifications also use such a system [4].

\subsection{Electric tail rotor}

Eurocopter Deutschland GmbH (now Airbus Helicopters) invented a special type of an electrically driven tail rotor or

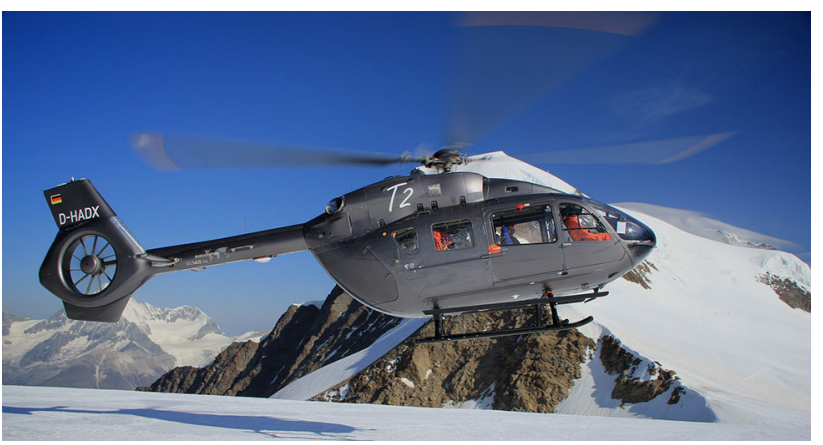

Fig. 2 H145 [@Airbus Helicopters (Carl Ockier)] better say fenestron for helicopters [5]. There is a housing around the tail rotor and at least one, or preferably two, permanent magnet energised synchronous engines are used for impellent. The synchronous engine is integrated as a torus around an opening of the housing. The blades of the tail rotor are fixed to a rotating component of the engine. The blade pitch control means are provided at the torus. The design ensures that the rotational speed of the rotor can be changed according to the current flight situation and requirement of tail rotor thrust. Additionally, the pitch of the rotor blades can be adjusted. A highly efficient tail rotor system is obtained due to the combination of pitch and speed control. The power supply and control of the system is not part of the invention.

\subsection{Heavy lift rotorcraft systems}

The National Aeronautic and Space Administration (NASA) initiated the "Heavy Lift Rotorcraft System Investigation" [6] programme in 2005. This study investigated different rotorcraft configurations for passenger transport in short and middle range flights. Three concepts were investigated. One was a "Large Advancing Blade Concept" that used a co-axial main rotor with additional propellers for propulsion. The second was a "Large Civil Tandem Compound", that was a compound rotorcraft with two main rotors in tandem configuration and additional propellers as well as fixed wings. The third was a "Large Civil Tiltrotor" concept. A sketch is of the rotorcraft is given in Fig. 3. The investigation identified the Large Civil Tiltrotor as the configuration with the best potential to be economically competitive, with the potential for substantial impact on the air transportation system. The design is able to transport 90 passengers within a range of $1850 \mathrm{~km}$ with a cruse flight speed of $155 \mathrm{~m} / \mathrm{s}$. In this study a variable speed rotor with a speed range of $50 \%$ was required, to reach an economically competitiveness.

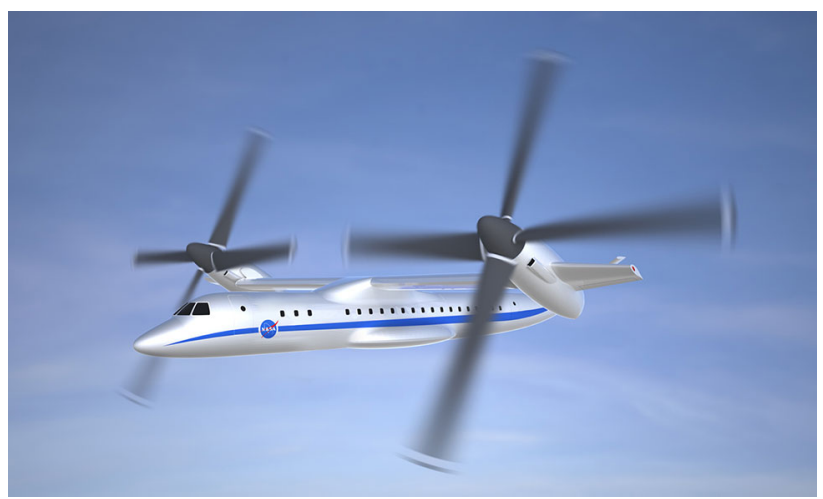

Fig. 3 NASAs large civil tiltrotor concept [@NASA Glen Research Center] 


\subsection{Turbine efficiency}

Misté and Benini [7] made a study about turboshaft engine performance for variable speed rotors using fixed or variable ratio transmission systems. The basic idea was to operate the turboshaft engine in the optimum range, independent of the current flight situation. This is only possible by using a variable transmission ratio gearbox. There they showed that a reduction of fuel consumption up to $13 \%$ is possible by using variable ratio transmission system. This number is only valid when the gearbox has no additional weight.

\section{Technology consideration}

\subsection{Modelling}

Conventional helicopters produce their lift and propulsion with a main rotor. Main rotor and tail rotor are driven by a turbine with constant speed while power transmission is conducted by a constant transmission gearbox. Using constant rotor speeds during operation requires a less complex blade design for this single design point. Eigenfrequencies and rotor harmonics are separated. This leads to good dynamical behaviour. Eigenfrequencies only cross through harmonics while accelerating the rotor up to its nominal speed. This is usually performed without blade loading, using zero collective and cyclic control. Both lift $\mathrm{d} L$ (1) and drag $\mathrm{d} D$ (2) of a blade depend on the flow speed at the blade section $v$, the air density $\rho$, the chord $c$ of the blade, radial length of the blade section dy and the lift coefficient $C_{\mathrm{L}}$ or the drag coefficient $C_{\mathrm{D}}$, respectively.

$\mathrm{d} L=\frac{\rho}{2} v^{2} c C_{\mathrm{L}} \mathrm{d} y$

$\mathrm{d} D=\frac{\rho}{2} v^{2} c C_{\mathrm{D}} \mathrm{d} y$

A high lift to drag ratio is intended for an efficient blade design (see Fig. 4) [2].

Figure 5 shows the power requirements of a helicopter with various flight speeds. The total rotorcraft power (circle line) consists of induced power (crossed line) (3), parasite power (starline) (4) and profile power (dotted line) (5). These can be calculated as follows [8]:

$$
\begin{aligned}
& P_{i}=\kappa \sqrt{\frac{T^{3}}{2 \rho \pi} \frac{1}{R}} \\
& P_{p}=\frac{1}{2} \rho V_{\infty}^{3} C_{\mathrm{Dp}} A
\end{aligned}
$$

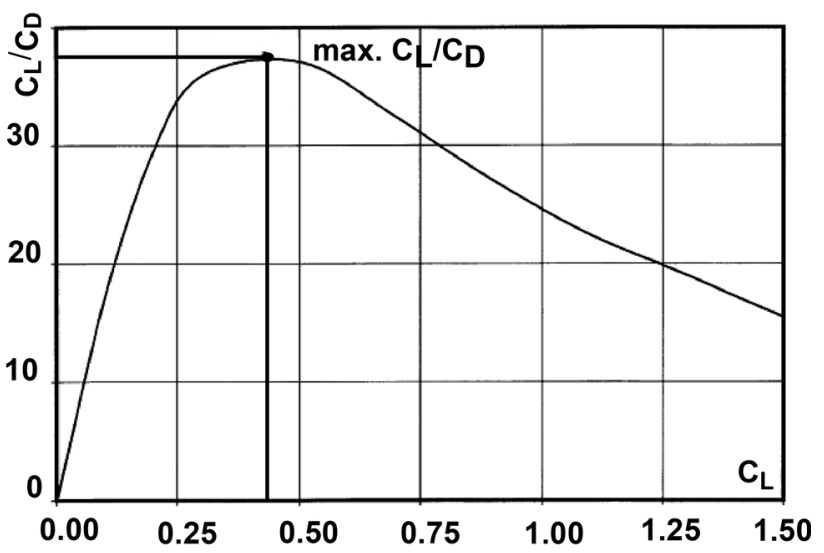

Fig. 4 Lift-over drag coefficient drawn over lift coefficient for a typical rotor blade [2]

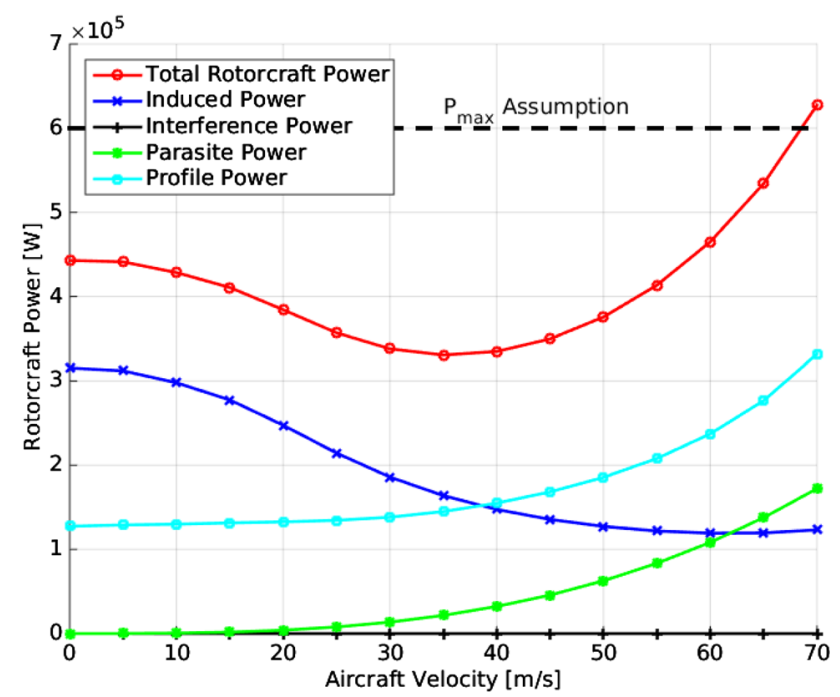

Fig. 5 Power requirements of a helicopter with various flight speeds

$P_{0}=\frac{1}{8} \rho A V_{\mathrm{TIP}}^{3} \sigma C_{\mathrm{D} 0}\left(1+4.65 \mu^{2}\right)$

$\mu=\frac{V_{\infty}}{V_{\mathrm{TIP}}}$

where $R$ is the rotor radius, $A$ is the rotor disk area, $\kappa$ the induced power coefficient, $T$ the rotor thrust, $\mu$ the advance ratio of the rotorcraft, $V \infty$ the rotorcraft velocity, $V_{\mathrm{TI}}$ the blade tip speed, $C D p$ the drag coefficient of the whole aircraft, $C$ the drag coefficient of blade profile at zero lift and $\sigma$ the solidity of the rotor. Hover and low speed flight are dominated by the induced power while the parasite power increases significantly with the third power of flight speed. Profile power increases with the third power of the rotational speed. Thus, profile power is highly dependent on rotational speed. Parasite power and profile power dominate high speed flight conditions. 


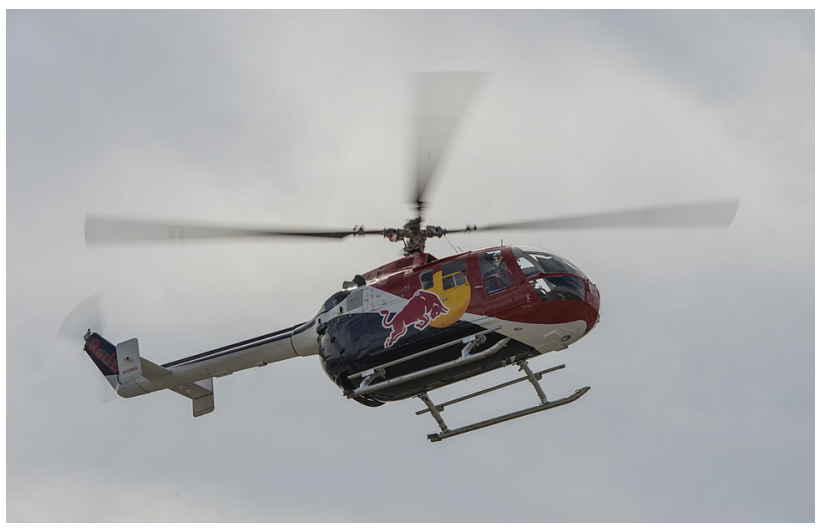

Fig. 6 BO 105 [〔 Airbus Helicopters (Jay Miller)]

Table 1 Parameters of the generic model

\begin{tabular}{ll}
\hline Number of blades $\left(N_{\mathrm{B}}\right)$ & 4 \\
Radius & $4.92 \mathrm{~m}$ \\
Cord & $0.2705 \mathrm{~m}$ \\
Airfoil & NACA23012 \\
Weight & $2400 \mathrm{~kg}$ \\
\hline
\end{tabular}

The calculations herein were performed by implementing a generic physical model of a helicopter similar to the Bo105 (Fig. 6) in CAMRAD II. Positions and geometries of the generic model were provided along with the required aerodynamic parameters. The parameters of the generic model are given in Table 1. CAMRAD II is an aeromechanical analysis of helicopters and rotorcraft that incorporates a combination of advanced models, including multibody dynamics, nonlinear finite element structural dynamics, and rotorcraft aerodynamics [9]. Nominal rotor rotational speeds are $\Omega_{\text {main }}$ Rotor $=424$ RPM and $\Omega_{\text {tail }}$ Rotor $=2220$ RPM. A NACA23012 was used as an airfoil. Aerodynamic coefficient tables representing the fuselage as well as the vertical and horizontal stabilisers were approximated.

\subsection{Gearbox technology}

The concept of using a gearbox with variable ratio has been employed since the 1980s by Moore [10]. His invention and some other ideas and inventions are summarised below.

Shifting gears during flight in a rotorcraft is a complex and difficult task, because the transfer of power must be secured while shifting and a speed change of the rotor should not be abrupt. Hence, continuous solutions may be favoured to ensure not only a smooth speed variation but also that the turbine works at its intended design point.

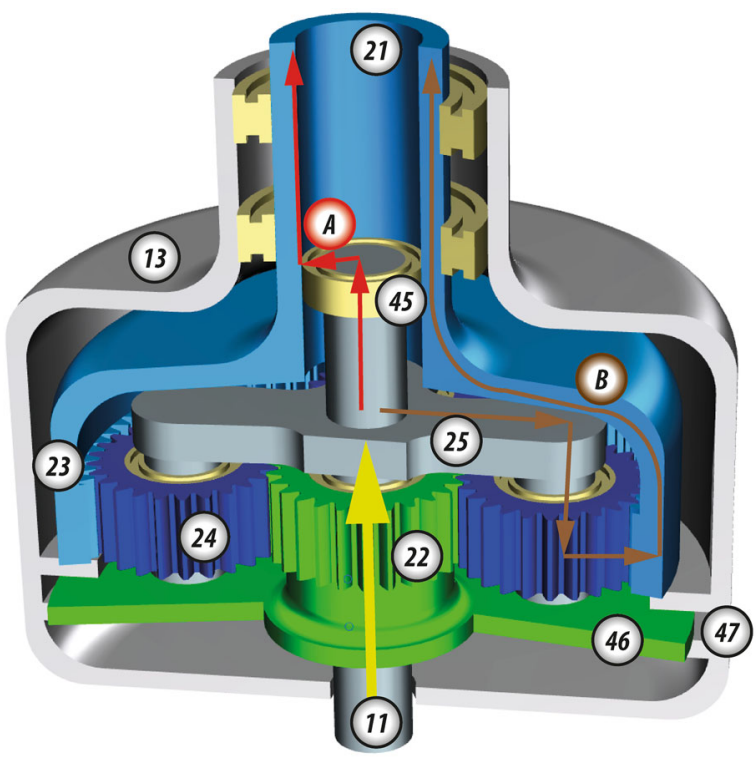

Fig. 7 Sectional view of a model based on Moore's invention

\subsubsection{Helicopter transmission system}

Moore [10] was one of the first researchers to identify the advantages of a variable rotor speed by using a variable transmission gearbox. In 1986, he invented a gearbox with two gear ratios, suitable for helicopters.

The system basically consists of a planetary gear, an overrunning clutch and a break system (see Fig. 7). It receives power form the input shaft 11 . The input shaft 11 is connected to the planet carrier 25 . The ring gear 23 is connected to the output shaft 21 . The output shaft 21 is rotatably mounted within housing 13 . The sun gear 22 is rotatably mounted to the input shaft 11 and is connected to the brake ring 46 . The hydraulic brakes 47 are mounted in the housing 13 .

If the hydraulic brakes 47 are open (A), the sun gear is able to rotate relative to the housing 13 . In this case, the planet carrier 25, the ring gear 23 and the sun gear 22 all rotate at the same speed. The power is transmitted from the input shaft 11 by the overrunning clutch 45 to the output shaft 21 . The output shaft operates at the same speed as the input shaft.

If the hydraulic brakes 47 are engaged (B), there is no rotation form the sun gear 11 relative to the housing 13 . The planetary gears begin to rotate. Therefore, there is relative movement between the sun gear 22 and the planet carrier. This causes relative movement between the ring gear 23 and the planet carrier 25. Due to the configuration, the ring gear 23 rotates at a higher speed than the planet carrier 25 and the input shaft 11 . Power is transmitted from the input shaft. 
11 to the planet carrier 25 across the planet gears 24 to the ring gear 23 and the output shaft 21 . The overrunning clutch 45 does not transmit any power or moment. Consequently, the output shaft 21 runs at a higher speed than the input shaft 11. It is not possible to enable a lower speed than the input speed. This is the main drawback of this invention.

\subsubsection{Two speed transmission with smooth power shift}

In 2006, Ai invented a system for smooth shifting with high efficiency [11] (see Fig. 8). The system consists of two planetary gears, U1 and U2, which are connected via a common planet carrier 16 and two electric motors, 3 and 4. The power input shaft 7 is connected with the sun gear of the first planetary gear. The output shaft 17 is connected with the sun gear of the second planetary gear. The two planetary gears $\mathrm{U} 1$ and $\mathrm{U} 2$ are connected via the planetary carriers 16 . The ring gears 10 and 13 are equipped with a locking device. The electric units 3 and 4 are also connected with the ring gears 10 and 13 . One ring gear is always locked during operation. When there is a request for changing the gear ratio, the locked ring gets unlocked. So both rings are able to rotate. One electric machine decelerates one ring gear. With the energy of deceleration the second electric unit accelerates the second ring gear. When the revolution of the first ring gear is almost zero the ring becomes locked and the other transmission is then used. The change of the transmission ratio is because of different numbers of teeth of the planetary gears.

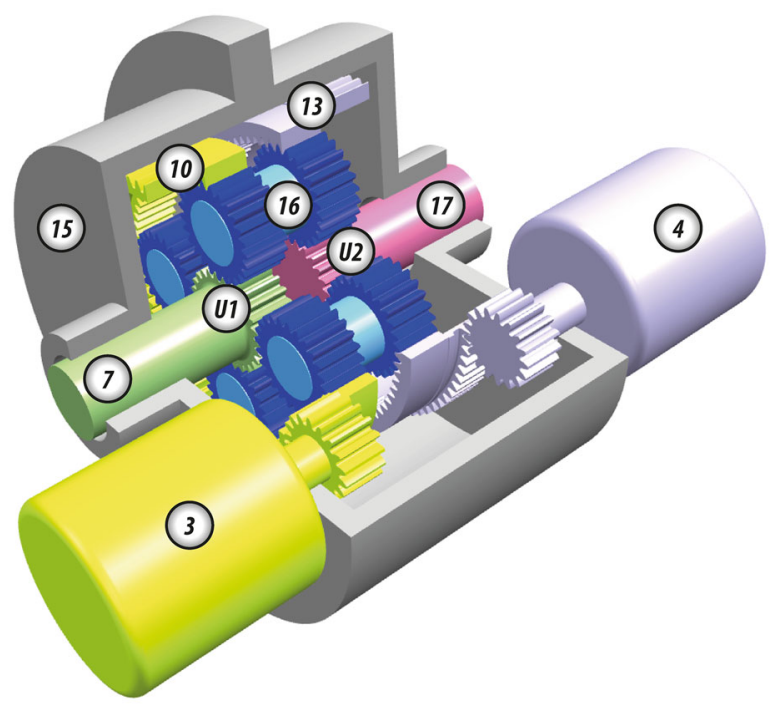

Fig. 8 Sectional view of a model based on Ai's invention

\subsubsection{Concepts for variable/multi-speed rotorcraft systems}

The outcome of NASAs "Heavy Lift Rotorcraft System" [6] research programme, as mentioned in Sect. 1.4, prompted various research projects related to rotor speed variation, including the project "concepts for variable/multi-speed rotorcraft systems" [12], which was concerned with the identification of multispeed transmission concepts. NASA invented three types of speed variation with two gears and a speed range of up to $50 \%$. By using a controller unit, these concepts are able to work as a continuously variable transmission. A smooth change of the transmission ratio makes a continuously working gearbox interesting for rotor-craft.

2.2.3.1 Concept 1 -inline tow speed planetary The system consists of a planetary gear, an overrunning clutch and a standard clutch. The working principle is similar to the device invented by Moore [10]. The sun gear is connected to the input shaft and the output shaft via the clutch. If the clutch is locked, there is a 1:1 transmission and the overrunning clutch turns free. If the clutch is open, power is transmitted from the sun gear via the still standing planet carrier to the ring gear and then over the overrunning clutch to the output shaft. The transmission ratio in this instance is $2: 1$. But the direction of revolution would be reversed relative to the first device. To avoid this occurrence, a double planetary system is used. The system is shown in Fig. 9.

2.2.3.2 Concept 2-offset compound gear This concept, given in Fig. 10, is based on an inline two speed planetary system. It uses an offset compound gear instead of the complex double planetary system. The gear on the input shaft, former sun gear, meshes with the ring gear part of the offset compound gear. At the other end, the offset

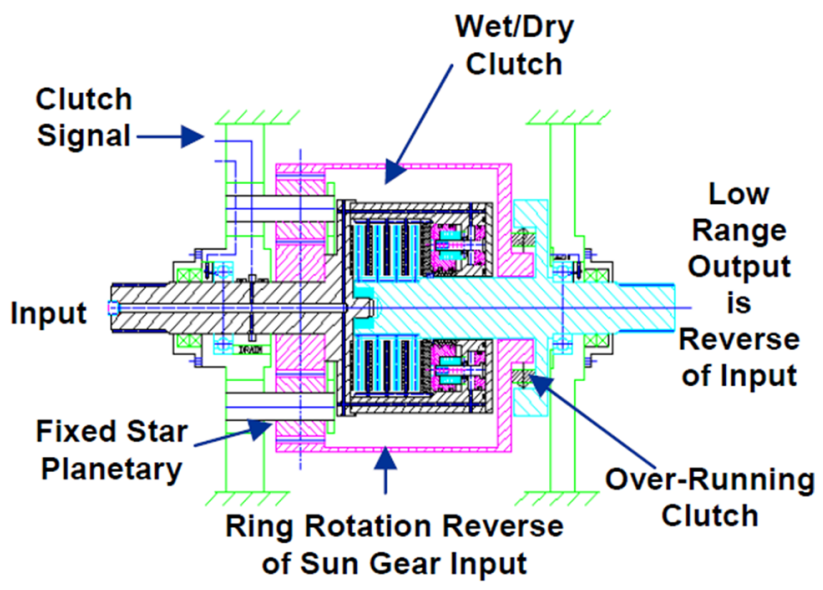

Fig. 9 Inline two speed planetary [@NASA Glen Research Center] 


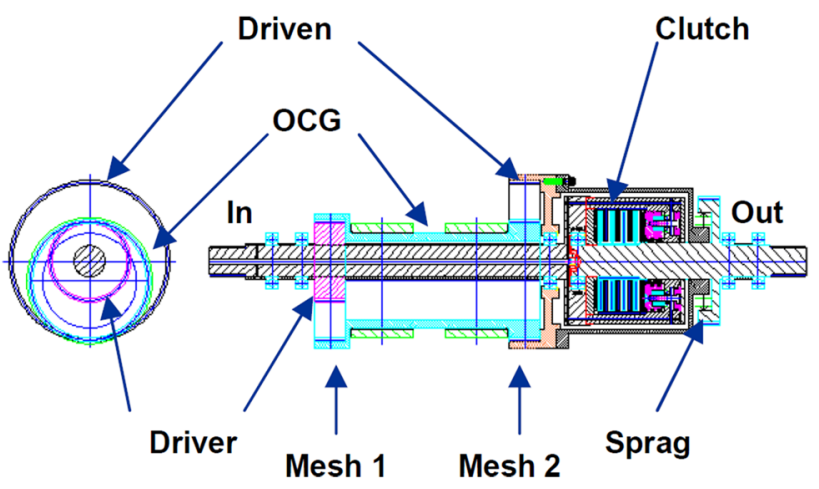

Fig. 10 Offset compound gear [@NASA Glen Research Center]

compound gear meshes with the ring gear from the former planetary gear system. This system has the ability to have a $1: 1$ transmission via the input shaft, the clutch and the output shaft or a 2:1 transmission via the gear on the input shaft, the offset compound gear, the ring gear and the overrunning clutch to the output shaft.

\subsubsection{Concept 3-planetary differential drive This} concept consists of a planetary gear and a controller or variator. The input shaft is connected to the sun gear; the output shaft is connected to the planet carrier; and the controller is connected to the ring gear. By changing the speed of the controller, the speed of the output shaft is also changed without altering the speed of the input shaft.

The system also functions with a variator. In this case, there are two planetary gears. The input is connected to the sun gear of the first planetary gear; the planet carrier of the first planet gear is connected to the sun gear of the second planet gear; and the planet carrier of the second planet gear is connected to the output shaft. The ring gear of the first planet gear powers the variator, which changes the speed of the second ring gear and, therefore, forms the output shaft. A drawing is given in Fig. 11.

\subsubsection{Power transmission apparatus for helicopters}

In 1999 the Advanced Technology Institute of CommuterHelicopter (ATIC) invented a continuous variable transmission system (CVT) that promises to be suitable for main and tail rotors of helicopters [13]. It is called "Power transmission apparatus for helicopter". The CVT system is a roller toroidal transmission combined with planet gears.

Roller toroidal transmissions (see Fig. 12) are friction gears that consist of a driving disc (1) on the input side, a driven disc (2) on the output side and some rolls (3). The rolls are in a concentric circle between the discs and are able to rotate around their axis. The axis (4) of the rolls can be tilted. By tilting the axis the radius between the rolls and

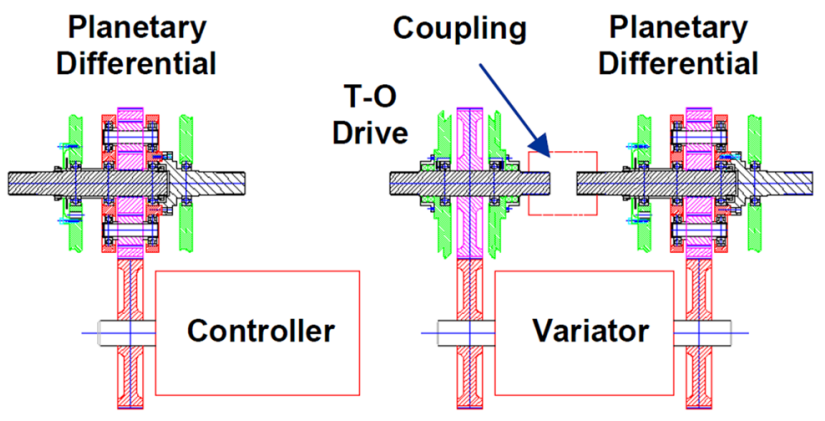

Fig. 11 Planetary differential drive [CNASA Glen Research Center]

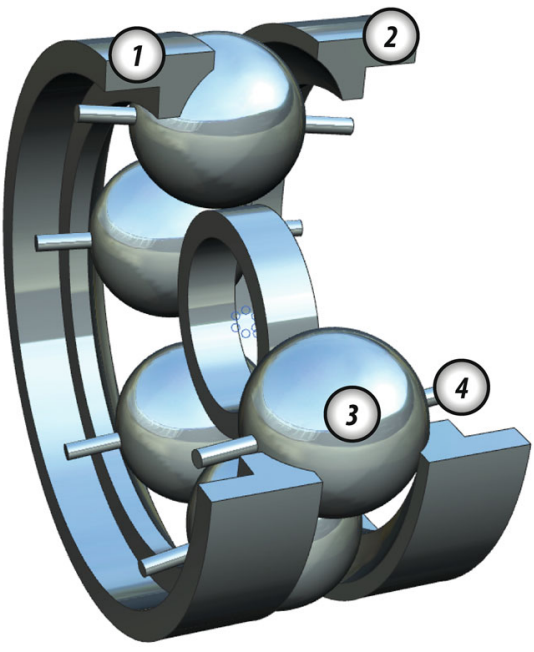

Fig. 12 Principle drawing of a roller toroidal transmission

the driving disc and the driven disc is changed. Due to this change in the radius, the transmission ratio is altered. This system is frictional and does not provide a positive traction. The background of this invention is a commuter helicopter.

\subsubsection{Concept study based on NASA concepts}

Based on work performed by NASA, Georgia Institute of Technology developed a high speed rotorcraft design for which a variable speed transmission with a planetary gear system was used [14]. This is a coaxial rotor helicopter with a pusher propeller fan. With variable speed transmission, the conceptually designed helicopter is able to fly $20 \mathrm{~m} / \mathrm{s}$ faster and can attain a maximum speed of $130 \mathrm{~m} / \mathrm{s}$.

\subsubsection{Further inventions}

Another example is the patent of Sikorsky Aircraft Corporation [15]. There are also inventions by Eurocopter [16] and Karem Aircraft [17] that use two or more gear transmissions. 


\section{Results}

\subsection{Efficiency}

The advantage of drive train with variable rotor speed regulation can be seen in Fig. 13. This figure shows the power requirement for various flight speeds with constant rotor speed (solid line) over the range of velocities, calculated in every given flight state. The calculation results are received using the generic model form chapter 2.1. It includes the rotor dynamics behaviour and trims on targeted flight conditions. The lower line (dashed line) shows the calculated power requirement using an optimal rotor speed in every given flight state. Rotor rotational speed increases with flight speed to account for the increase in lift. Power reduction is a result of reduced profile power. This parameter sensitivity study reveals that a reduction of $23 \%$ of the total rotorcraft power is possible at flight conditions that support maximum flight duration.

The proposed benefit in power must, of course, paid for by additional weight from a variable speed gearbox. Additional weight reduces the payload of the helicopter and therefore reduces the increase in power benefit.

The final power reserve may be used for saving fuel and ecological efficiency. The flight envelope may also be extended, such as flight speed, duration, range and manoeuvrability.

\subsection{Flight envelope: Increase of flight speed}

This section gives estimates of the reduction in total rotorcraft power due to varying the rotor speed at fast forward flight. A trimmed forward flight with $70 \mathrm{~m} / \mathrm{s}$ has a total power requirement of $630 \mathrm{~kW}$, shown in Fig. 5. The trimmed rotor thrust (upper) and power (lower) on $7.5^{\circ}$ collective pitch is given in Fig. 14. Maximum power available for the main rotor is estimated to be $600 \mathrm{~kW}$. Hence, the flight condition cannot be reached with a nominal rotor speed of 424 RPM (Fig. 13). The power demand for the constant rotor speed is in all given points higher for the constant rotor speed. This is because the results are only for forward flight. Other flight conditions, like climb or manoeuvre flights while not considered here, require that higher RPM value.

The helicopter can be designed for multiple flight conditions but optimised only for one flight condition. Of course all other conditions are not optimal. A variable speed technology would benefit this.

Assuming that a collective pitch of $10^{\circ}$ increases the rotor thrust, one can decrease the rotor speed to have the same thrust that is necessary for a flight at $70 \mathrm{~m} / \mathrm{s}$. Thrust and rotor speed have a linear correlation (upper graph in Fig. 14) but rotor speed and power have a polynomial (cubic) correlation (lower graph in Fig. 14). In the example given here, the rotor rotational speed is decreased to $82 \%$ of the nominal speed and power is reduced by $40 \%$ for the same output thrust. The profile power of the rotor is reduced by $130 \mathrm{~kW}$ and the optimised total rotorcraft power is $500 \mathrm{~kW}$. The variable speed rotor technology allows an operational speed of $70 \mathrm{~m} / \mathrm{s}$ and creates the potential to fly at even faster forward speeds. Further aspects will be investigated in the future in order to validate that other rotorcraft requirements, such as autorotation characteristics, retreating blade stall and pitch link load limits do not prevent higher speeds.

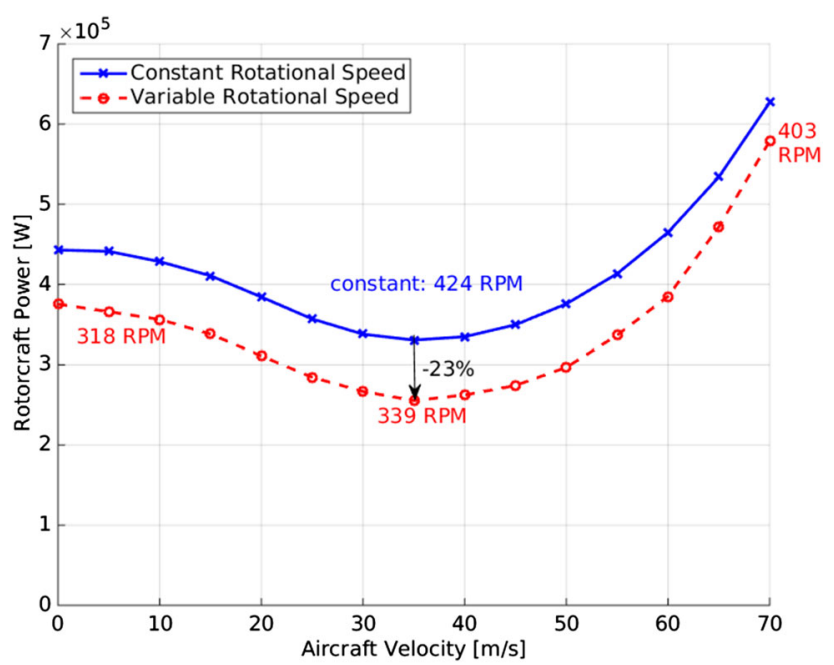

Fig. 13 Power demand with (dashed line) and without (solid line) variable rotor speed
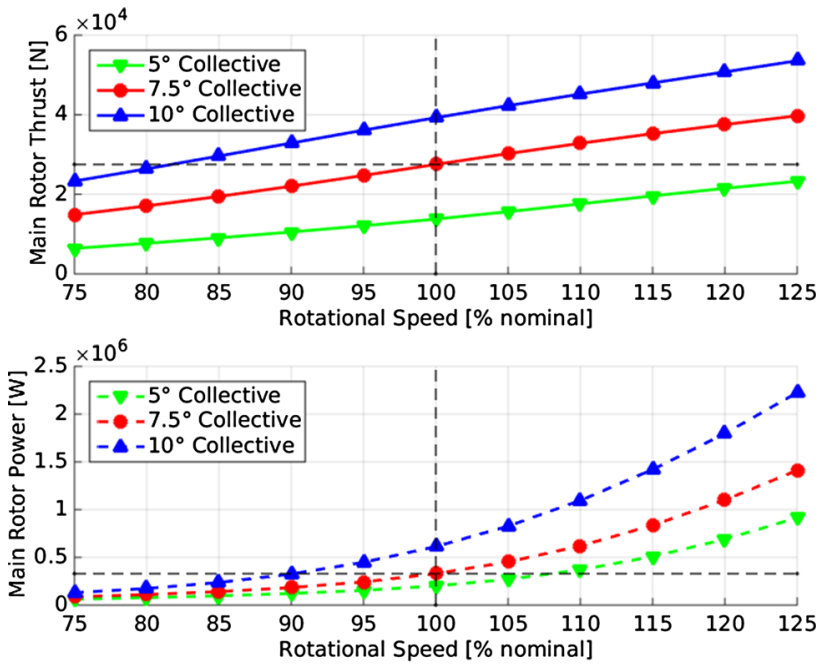

Fig. 14 Thrust and power of the main rotor 


\subsection{Flight envelope: extension of the ceiling altitude}

Considering a main- and tail rotor helicopter configuration, the thrust of the tail rotor can also be variable depending on its rotational speed. Figure 15 shows the requirements of the rotorcraft power, the main rotor torque and the tail rotor thrust while operating at various altitudes. To achieve a trimmed flight condition, the tail rotor thrust must be sufficient to counteract the torque of the main rotor, with the following relationship (7):

$M_{z, \text { mainRotor }}=T_{\text {TailRotor }} I_{\text {LeverArm }}$

The lever arm in the chosen model is $5.5 \mathrm{~m}$. The tail rotor has sufficient thrust for a hover ceiling of $4000 \mathrm{~m}$.

The tail rotor is limited to altitudes $>4000 \mathrm{~m}$ because it cannot provide enough thrust to counteract the torque of the main rotor. Stall limits are reached for a further increase of the collective pitch control of the tail rotor. Here, only the antitorque partition of the tail rotor thrust was analysed. The tail rotor thrust capability must be even higher than the antitorque balance due to the required yaw rate margin.

Extending the flight envelope to higher ceiling requires increased tail rotor thrust. Hence, without affecting the rotor geometry, one can simply increase the rotational speed of the rotor. Figure 16 shows the tail rotor thrust and power for various altitudes and three rotor speeds. Thrust reduction due to lower density in higher altitudes can be controlled by varying the rotational speed. This results in higher ceiling levels for the rotor-craft range of operations. A sufficiently powerful engine supply is assumed as the
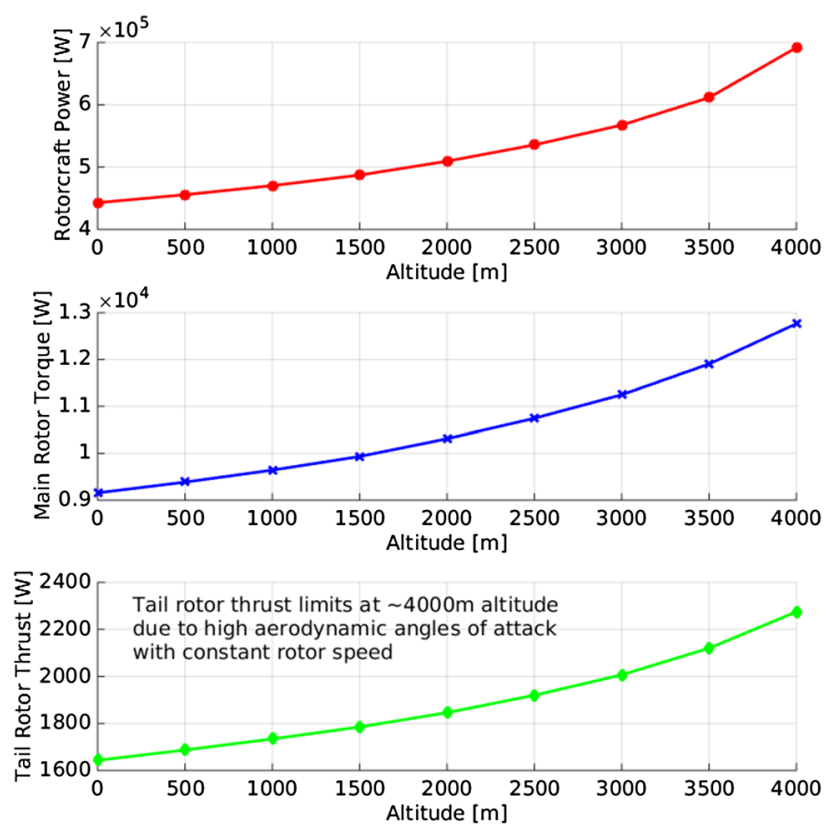

Fig. 15 Hover ceiling altitude limits
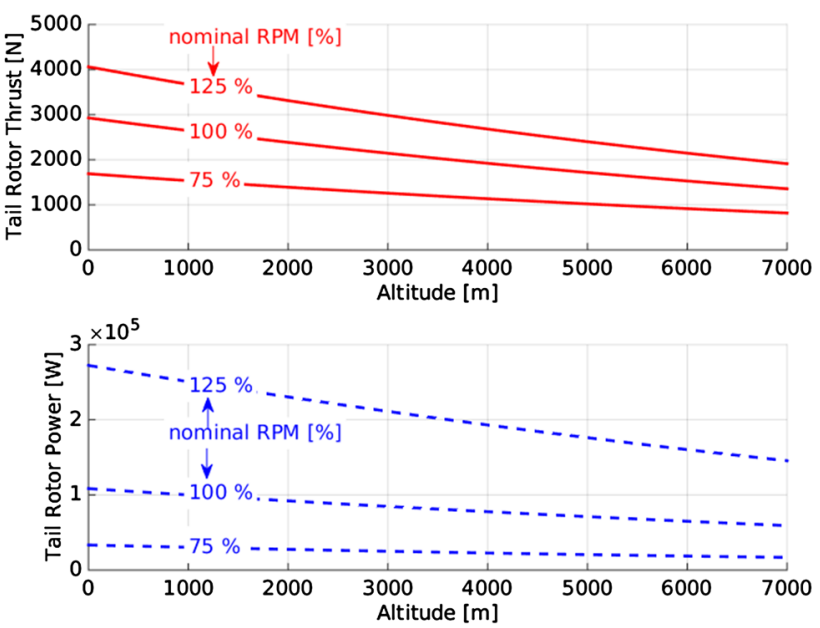

Fig. 16 Thrust and power of the tail rotor

power grows as a cubic function while thrust increases linearly. The conclusion is that the tail rotor, as previously mentioned for the main rotor, can be thrust optimised in accordance with the individual flight state.

\subsection{Rotor-dynamic behaviour}

The dynamic behaviour of a rotor characterises the vibratory loads of the whole helicopter. Rotor blades are, as a rule, designed so that its flap, lag, and torsional Eigenfrequencies do not match with the rotor harmonics at nominal rotor speed.

Figure 17 shows the frequencies of a stiff-in-plane (1st lag frequency above $1 \Omega$ ) rotor blade. Frequencies are mapped with varying rotational speed and rotor harmonics are presented as dashed straight lines. The rotor, which rotates with nominal $7.3 \mathrm{~Hz}$, has its first harmonic $1 \Omega$ at this very frequency, its second $2 \Omega$ at $14.6 \mathrm{~Hz}$, its third $3 \Omega$

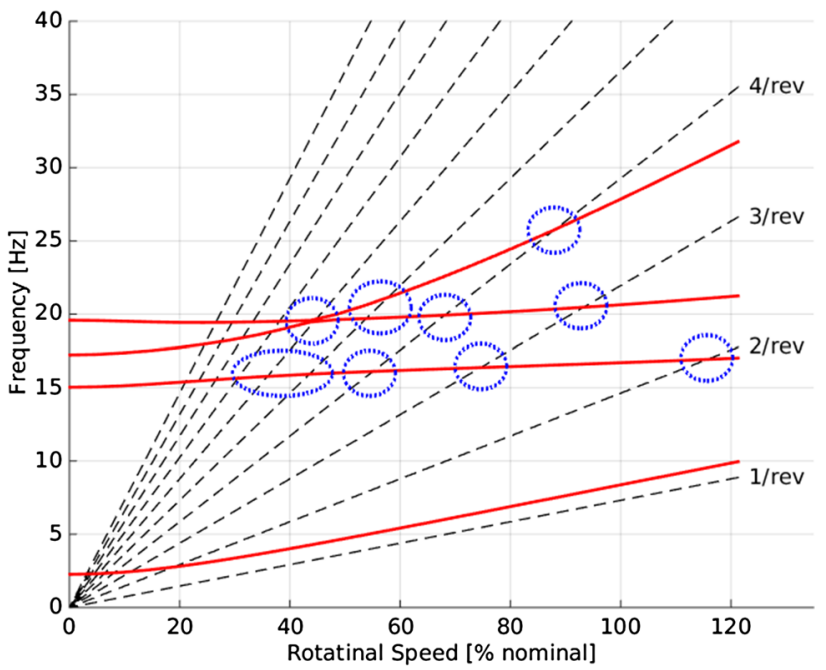

Fig. 17 Frequency diagram 
at $21.9 \mathrm{~Hz}$, etc. The progressive rise of lag and particularly flap frequencies is caused by structural stiffening through centrifugal forces. Tuning of blade frequencies is usually performed by varying the structural properties of the blade and by using tuning weights along the blade. It can be safety-critical if any low rotor Eigenfrequency should correspond to a harmonic. Resonance from rotor structure coupling effects can significantly influence the fatigue strength of safety-critical helicopter components. Furthermore, air resonance can also lead to a resonance catastrophe. The $\left(N_{\mathrm{B}}-1\right) \Omega, N_{\mathrm{B}} \Omega$ and $\left(N_{\mathrm{B}}+1\right) \Omega$ frequencies are particularly important for the vibrational control in the nonrotating frame. Those vibrational loads can increase significantly, when a resonance occurs. A safety factor of at least $\pm 10 \%$ should be allowed [18]. Based on these requirements, limitations may be expected for the operational use of the technology of variable rotor speeds. An up-to-date and innovative blade design is essential for the safety and the failure performance of the system. Modern materials such as carbon fibres or glass fibres as well as a smart build-up sequence over the blade profile are used in order to develop low vibrating rotor blades. Material and strength characteristics are not fully understood yet. Modern materials will give better effects using mass distribution and form of blade and will therefore also benefit the development of variable speed rotor systems. With respect to tuning of blade frequencies, multiple cases should be differentiated:

The rotor can be calibrated to a design point if the intention is to operate with constant rotational speed. Resonances must be avoided.

Operation with few specific rotational speeds that are used by shifting gears requires to tune the rotor for multiple design points. Resonances must again be avoided. The rotor will be relieved from loads while shifting between gears. Harmonics are passed through as fast as possible; therefore, the change of gear should be in a flight state with enough power reserve.

The use of continuous gearbox systems offers the possibility to operate with an arbitrary rotational speed. As a consequence, the rotor system must be able to be operated with loadings at or close to a rotor harmonic. High vibratory loads must be tolerated. Hence blade design concerning stability and stiffness is essential. Possible solutions may be to use active damping systems or rotational speed controller. Thus, rotational speeds can be changed continuously and dynamic critical areas are avoided by active regulations. The system is dynamically controlled to its lower or higher frequencies in order to avoid the harmonics. An effective and optimised operation can, however, be established over the whole range of flight states. System vibrations are minimised and maintenance costs can be controlled and kept at a minimum.

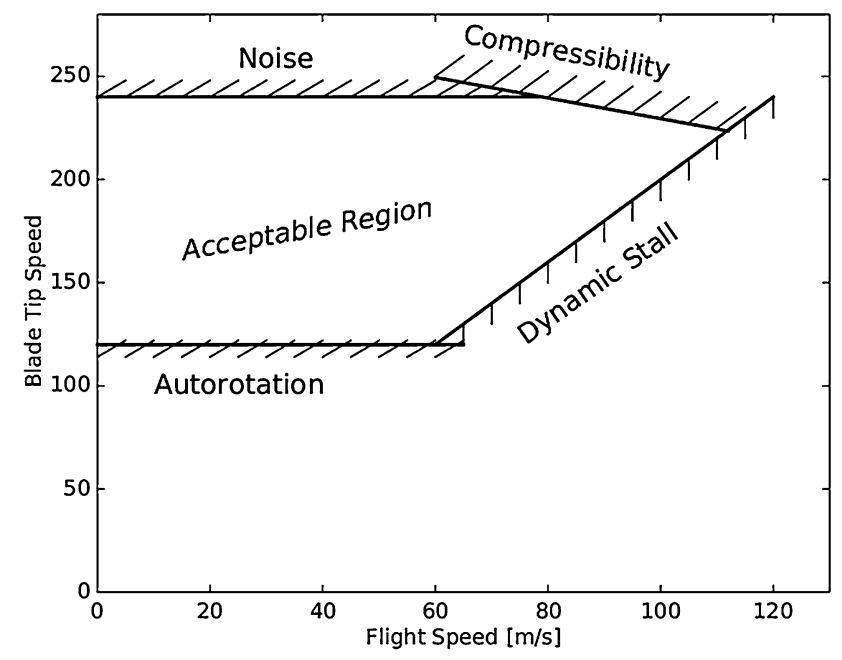

Fig. 18 Limitations of the flight envelope

The variation of rotor speed may be accomplished within the framework of feasibility, certification specifications and compliance with general limitations of the flight envelope (see Fig. 18). A rotational speed that is too low may not comply with the autorotation requirements. A rotational speed that is very high affects noise limits. Compressibility effects may occur in high speed flight condition. To counteract a retreating blade stall, the rotational speed of a rotor must also have a minimum in high speed flight. The aforementioned limits are based on physical requirements as well as on safety and certification standards. Within these limits, one can implement system optimisation with variable speed rotor technologies. Modern materials such as carbon fibres or glass fibres as well as a smart build-up sequences over the blade profile and radial are used to develop low vibrating rotor blades. Material and strength characteristics are not fully understood yet. Modern materials will give better effects using mass distribution and form of blade and will therefore also benefit the development of variable speed rotor systems.

\subsection{Gearbox-technology consideration}

As described above, there are multiple ways of changing the rotor speed of a rotorcraft. But how do such systems function during flight and what are their disadvantages?

Firstly, gear shifting during flight of a rotorcraft has to be considered. Discontinuous transmissions are designed for single operation points. This is advantageous for the rotor design as there is one design point for every stage of the gearbox. E.g., a two-staged gearbox can be designed on hover and fast forward flight conditions. The mission profile for such a rotor-craft may appear as follows: Take off and hover in the first gear, accelerate and initialise the forward flight in the first gear. At some defined speed, there is a point 


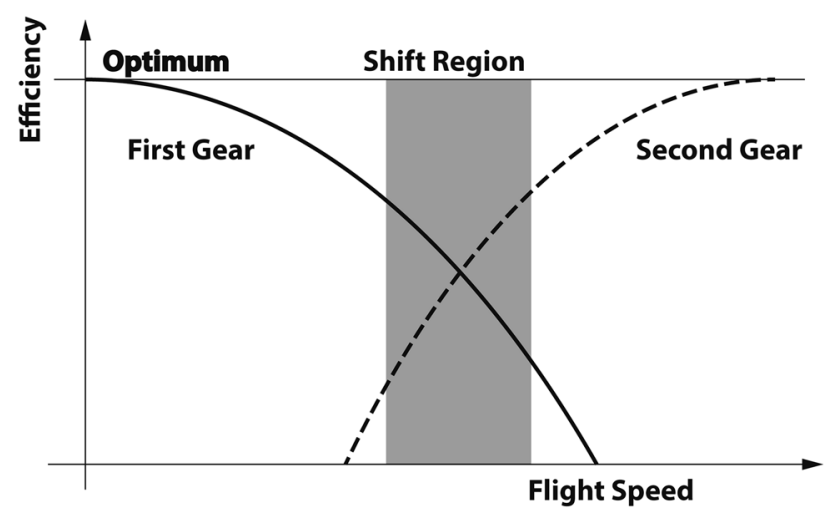

Fig. 19 Gear efficiency over flight speed

where the efficiency of the first gear is less than that in the second gear. The aircraft is then shifted into second gear. The helicopter then accelerates further until the travelling speed is reached and so the design point of the second gear is reached. The process is reversed during deceleration and landing. Figure 19 qualitatively gives the efficiency of a twostage transmission with varying flight speed.

The graph refers to varying rotor power and therefore varying optimal rotor speed. The minimum is caused by a decreasing demand of induced power from hover to moderate forward flight speed. At high speed, the power is dominated by the parasite and profile drag.

A shift leads to a change of speed and torque on the output shaft. This happens abruptly because one transmission element is engaged and another one is disengaged. The input is on a constant power and speed level. Shocks and vibratory loads affect the whole drive train. In order to avoid system failures, and to reduce vibrations and maintenance costs, it is necessary to enable smooth shifts. Also, for quick changes of flight states as in manoeuvres, a fast change of gear should be supported. This again may lead to shocks and high loading applied to the drive train.

By using a continuously variable transmission the turbine and the rotor can always be driven power optimised. The change of rotor speed can be performed in a smooth way, and it is much more adaptive than a shifting system. Shocks and vibratory loading can be reduced. The question is: how can a continuous variable transmission system be realised?

A disadvantage of frictional solutions is wear. Wear and thermal loading increase during high power flight states and therefore lead to a reduction of the maximal transferable power. This vicious circle continues, and in the worst case can result in total failure of the transmission system. Besides the technical problems, also the certification requirement has to be taken into account.

Electrical transmission systems have to be redundant because of their abrupt damage behaviour. This leads to a weight increase of the transmission system.
The power transmission depends on the viscosity of the fluid for a hydraulic continuous variable transmission. The viscosity of the fluid depends on the temperature of the fluid. The higher the temperature the lower the ability of the fluid to transmit power. The higher the transmitted power, the higher the temperature and the lower the ability of the fluid to transmit the power. This leads to an increase of the temperature. Due to overheating of the hydraulic, the entire transmission system can cease to function properly.

Hence, by using a variable transmission system in rotorcraft new failure scenarios appear, which must be considered carefully and specifications must be chosen accordingly. The efficiency of the rotorcraft increases due to the ability to set the rotor speed according to the current flight conditions. This way the turbine and auxiliaries can also operate in their design point. The required power of the rotor is optimised.

Hence, the additional weight must be considered as well. A variable transmission system is more complex than a single speed gearbox and therefore has an increased weight accordingly. Possible gains due to power optimisation from the rotor are decreased. NASA compared multiple variable speed systems in one of their studies [19]. A two-stage gearbox with variable speed turbines was investigated. This analysis showed that turbines have a good power-to-weight ratio. For their investigation NASA assumed a weight addition of $10 \%$ for a variable transmission gearbox and therefore was the option with the highest weight. The weight penalty for the gearbox is based on different studies from NASA [20]. All systems showed a difference in fuel consumption of only $5 \%$. The conclusion is that all systems that were compared have potential and a precise analysis is needed for each system.

\section{Discussion}

Multiple aspects benefit from the use of a variable speed rotor system for rotorcraft. Hence, the technology is needed under extreme conditions and may be an indispensable feature for future rotorcraft configurations. The following points support the necessity of a development of variable speed systems:

- Power efficient operation in arbitrary flight states.

- Fly longer.

- Fly further.

- Fly faster.

- Noise reduction.

- Ecologically efficient. Power optimisation reduces fuel consumption and thereby exhaustion and $\mathrm{CO}_{2}$ emissions.

- Reduced fuel consumption benefits global resources. Hence, it also reduces operating expenses. 
A rotorcraft usually does not work only at its design point. The angle of attack and power demands are set according to the flight state with a constant rotational speed. A variable speed system could reduce the power as well as noise from the blades, especially the blade tip noise emission. Fuel consumption can also be reduced as a matter of reduced power demands [7]. Considering global warming, this is also an ecological issue for future rotorcraft and generally in aerospace technologies. Based on previous considerations, the following fundamental requirements can be used to design a transmission variable gearbox.

\subsection{Continuous variable transmission}

The transmission ratio should be fitted according to the flight conditions to enable the rotor and the turbine to operate at their optimum operation point. The change of the rotor speed can be performed seamlessly with continuous variable transmissions.

\subsection{Minimal possible weight increase}

The increasing gearbox weight decreases the efficiency of the rotorcraft. One must ensure that this additional mass is as low as possible because the disadvantage of a weight increase could outweigh any advantage of this design.

\subsection{Independent power support of the auxiliary units}

The auxiliary units must be driven in their design point and be independent of the current flight situation. An efficient and secure usage must be guaranteed.

\subsection{A speed regulation for every rotor}

Each rotor, depending on the rotorcraft configuration, should have the possibility to operate at its optimum speed.

\subsection{Secure power transmission}

The transmission system has to transmit the power securely. System failures must be avoided during the whole design process.

\subsection{Efficient system}

The transmission system has to be highly efficient. If the efficiency of the transmission system cannot be ensured, the benefit of the speed variation is negligible.

\subsection{Certification specification}

The system development must be oriented according to the certification specification. The specifications require special tests and checks that must be considered and conducted [CS-29.923(n)] [21].

The results presented above are based on a single main rotor and tail rotor configuration as shown in Fig. 20. The main rotor produces the force for lift and forward flight. It is controlled by the collective and cyclic blade control. The primary function of the tail rotor is to compensate the indicated moment of the main rotor. Furthermore, it is used to control the yaw motion. Based on the certification specifications many modern helicopters use two engines. The power is collected in the main gear box and then separated to the main and tail rotor. Additional auxiliaries are driven by the main gearbox. This must be considered by designing a speed variable configuration.

Figure 21 shows a compound helicopter configuration based on the $X^{3}$ demonstrator from Airbus Helicopters that had its first flight in 2010. The helicopter uses a main rotor for lift and it has two additional pulling propellers for horizontal thrust. By using a variable transmission, it is necessary to have an individual control of the propellers and the main rotor. Hence, it is possible to operate the helicopter in a power optimum area and extend the flight envelope.

The given compound configuration has advantages in fast forward flight. By using a variable transmission, it is possible to increase the speed of the propellers to increase the horizontal thrust for forward flight and to decrease the speed of the main rotor. Horizontal wings take over the vertical thrust during forward flight. Supersonic rotor tip speeds can thus be avoided.

This design can only result in an optimum by using variable transmission. The speed variation enables the rotorcraft to be operated power optimised in any flight

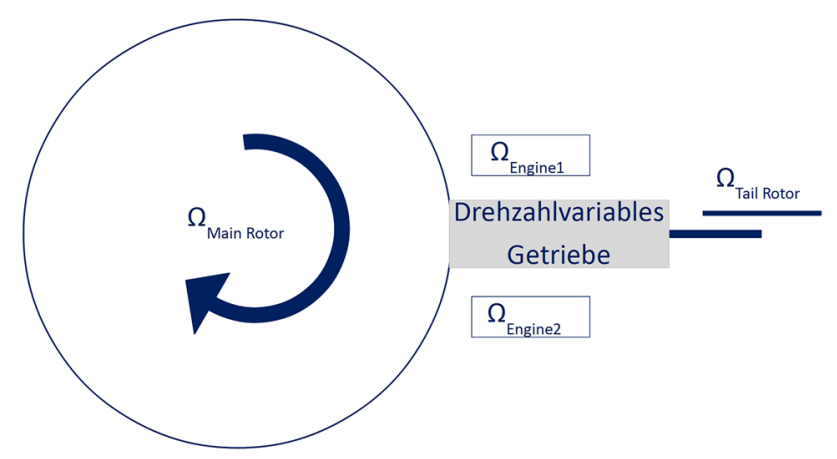

Fig. 20 Schematic of a single rotor configuration 

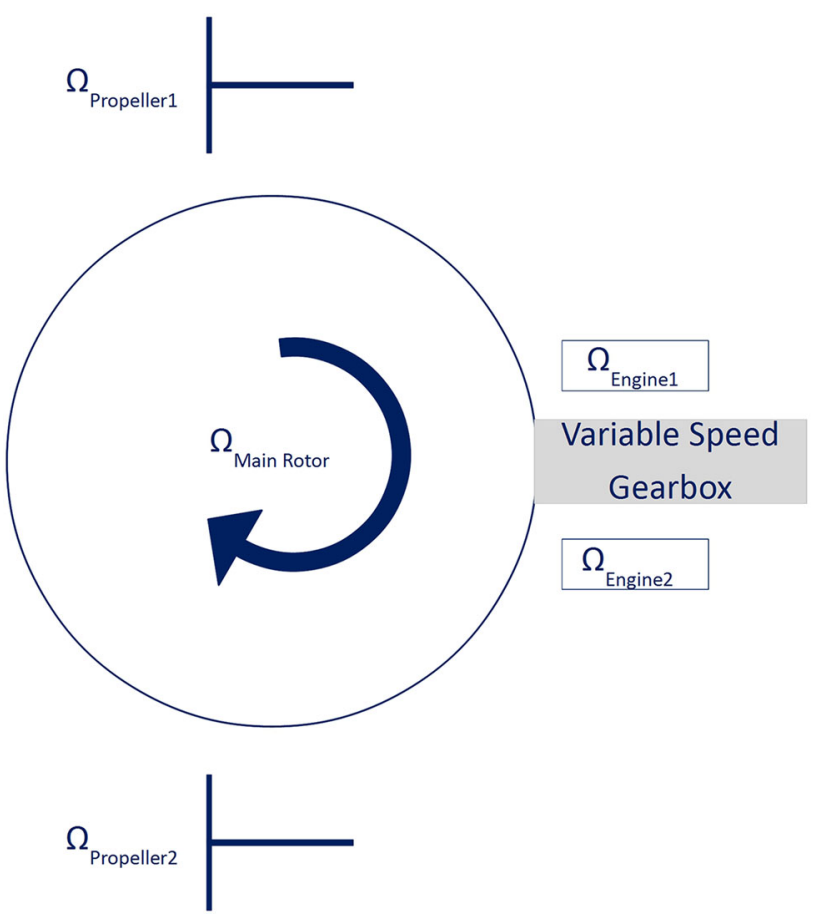

Fig. 21 Schematic of a compound rotor configuration

conditions and to reach higher forward flight speed characteristics.

\section{Conclusions}

It was shown that advanced research in the variable rotor speed technology may lead to a significant potential for various kinds of rotorcraft architectures. Due to international trends towards more power efficient, ecological and high performance rotorcrafts, it appears to be necessary to use speed variability in modern rotorcraft designs. The technology can be realised by using variable transmission gearboxes. These designs have a high speed range and enable an independent drive for each rotor or auxiliary at optimal turbine speed. Further research and development is needed to design and realise a drive system that complies with these requirements.

Acknowledgments Open access funding provided by TU Wien (TUW).

Open Access This article is distributed under the terms of the Creative Commons Attribution 4.0 International License (http://crea tivecommons.org/licenses/by/4.0/), which permits unrestricted use, distribution, and reproduction in any medium, provided you give appropriate credit to the original author(s) and the source, provide a link to the Creative Commons license, and indicate if changes were made.

\section{References}

1. Putrich, G., Drrwing, C.: Farnborough: a160 technical description: shifting up a gear. Flight Int. 178(5248), 90-94 (2010)

2. Karem, A.E.: Optimum speed rotor. US Patent 6,007,298 (1999)

3. US Department Of Defence: Eurocopter EC145 UH-72 Lakota Helicopter Flight Manual (2008)

4. MIL Design Bureau: Mi-8-helicopter flight manual (2005)

5. Keßler, M., Altmikus, A.: Electrical powered tail rotor of a helicopter. US Patent 2013/0170985 A1 (2013)

6. Johnson, W., Yamauchi, G.K., Watts, M.E.: NASA heavy lift rotorcraft systems investigation. NASA Ames Research Center Langley Research Center, NASA/TP-2005-213467 (2005)

7. Misté, G.A., Benini, E.: Turboshaft engine performance comparison between CVT and fixed ratio transmission for a variable speed rotor. 39th European Rotorcraft Forum, Moscow (2013)

8. Johnson, W.: Rotorcraft aeromechanics. Cambridge University Press, Cambridge (2013)

9. Johnson, W.: Technology drivers in the development of CAMRAD II. American Helicopter Society aeromechanics specialists conference, San Francisco, California (1994)

10. Moore, R.E.: Helicopter rotor transmission systems. US Patent 4,632,337 (1986)

11. Ai, X.: Two speed transmission with smooth power shift. US Patent 7,044,877B2 (2006)

12. Stevens, M.A., Handschuh, R.F., Lewicki, D.G.: Concepts for variable/multi-speed rotorcraft drive system. Glenn Research Center Cleveland Ohio (2008) NASA/TM-2008-215276

13. Goi, T., Kawakami, K., Yamakawa E.: Power transmission apparatus for helicopter. European Patent 1038766 A2 (2000)

14. Ashok, S.V., Schrage, D.P., Wade, B.: Variable speed transmission using planetary gear system for high speed rotorcraft application. American Helicopter Society 66th Annual Forum, Phoenix (2010)

15. Palcic, P.X., Garcia, T., Gmirya, Y.: Variable speed transmission for a rotary wing aircraft. US Patent 7,942,365B2 (2011)

16. Vialle, M.: Power transmission gearbox presenting a modifiable speed of rotation at its outlet and a corresponding method of operation. US Patent 8,027,772B2 (2011)

17. William Martin Waide, W.M., Karem, A.: Rotor-craft engine and rotor speed synchronization. US Patent 8,020,803B2 (2011)

18. Bittner, W.: Flugmechanik der Hubschrauber. Springer, Berlin (2009)

19. Snyder, C.A., Acree, Jr. C.W.: Preliminary assessment of variable speed power turbine technology on civil tiltrotor size and performance. American Helicopter Society 68th Annual Forum, Fort Worth (2012)

20. Acree, C.W., Snyder, C.A.: Influence of alternative engine concepts on LCTR2 sizing and mission profile. AHS future vertical lift aircraft design conference, San Francisco, CA, January 2012

21. EASA: Certification specifications for large rotor-craft CS-29 (2012) 